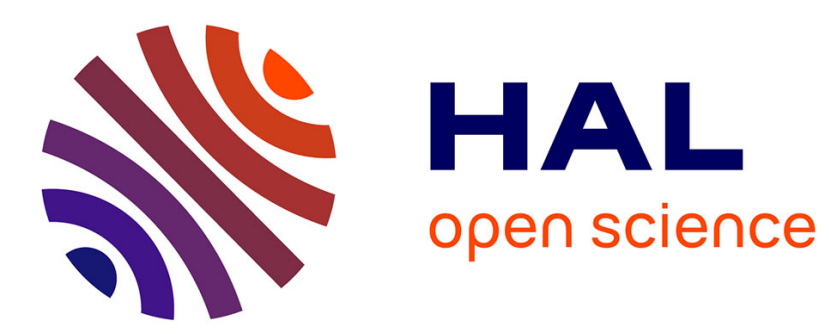

\title{
Mechanical Properties and Deformability During the Preforming of a flax reinforcement
} Pierre Ouagne, Damien Soulat, Gilles Hivet, Samir Allaoui

\section{To cite this version:}

Pierre Ouagne, Damien Soulat, Gilles Hivet, Samir Allaoui. Mechanical Properties and Deformability During the Preforming of a flax reinforcement. The 14th International Conference on Material Forming: ESAFORM 2011, Apr 2011, Belfast, United Kingdom. April 2011. hal-00655549

\section{HAL Id: hal-00655549 \\ https://hal.science/hal-00655549}

Submitted on 30 Dec 2011

HAL is a multi-disciplinary open access archive for the deposit and dissemination of scientific research documents, whether they are published or not. The documents may come from teaching and research institutions in France or abroad, or from public or private research centers.
L'archive ouverte pluridisciplinaire HAL, est destinée au dépôt et à la diffusion de documents scientifiques de niveau recherche, publiés ou non, émanant des établissements d'enseignement et de recherche français ou étrangers, des laboratoires publics ou privés. 


\title{
Mechanical Properties and Deformability During the Preforming of a flax reinforcement
}

\author{
P. Ouagne ${ }^{a}$, D. Soulat ${ }^{a}$, G. Hivet ${ }^{a}$, S. Allaoui ${ }^{a}$ \\ ${ }^{a}$ Laboratoire PRISME, University of Orleans, 8 Rue Leonard de Vinci, 45072 Orleans, France
}

\begin{abstract}
This paper presents one of the first experimental investigations on dry woven preform made of flax yarns with the view to analyze the formability of these reinforcements made of natural fibre. The specific preforming device is presented. It is constituted by a mechanical module designed to form severe geometries such as strongly double curved shapes. It is also constituted by an optical module to measure local strains during the forming process. An analysis of the defects at the scale of the preform, such as wrinkling or buckle and the measurement of the shear angle of the reinforcement is conducted in conjunction to a mechanical characterisation of the considered reinforcement. .
\end{abstract}

Keywords: Composites, Preforming, flax fabric, Natural Fibres.

PACS: 81.05.Qk Reinforced polymers and polymer-based composites

\section{INTRODUCTION}

Natural fibres have long been considered as potential reinforcing materials [1] or fillers in thermoplastics or thermosets composites. Natural fibres are particularly interesting because they are renewable, have low density and exhibit high specific mechanical properties. They also show non-abrasiveness during processing, and more importantly biodegradability. A large amount of work has been devoted to identify the tensile behaviour of individual fibres of group of few fibres of different nature and origin $[2,3,4,5]$. These works investigate the effect of several parameters such as the type of fibres, density, the fibre length, and diameter on the mechanical properties such as Young's modulus, tensile strength, failure strain [6]. The hierarchical organization and the extreme complexity of the fibre internal microstructure and its influence on the mechanical behaviour explain the large interest and the high number of studies carried out at the scale of the fibre. However, few studies deal with the subject of the mechanical behaviour of fibre assemblies such as yarn and fabric.

To manufacture high performance composite parts, it is necessary to organise and to align the fibres. As a consequence, aligned fibres reinforcements architectures such as unidirectional sheets, non-crimped fabrics and woven fabrics (bidirectional) can be manufactured. For woven fabrics, the forming possibilities of these reinforcements strongly depend on the mechanical properties of the yarns constituting them.

In the Liquid Composite Moulding (LCM) family, the Resin Transfer Moulding, (RTM) process has received a large attention in the literature [7]. The first stage of this process consists in forming dry reinforcements. In case of specific double curved shapes, woven fabrics are generally used to allow in plane strain necessary for forming without dissociation of the yarns. The modification of the yarn orientation and local variations of fibre volume fraction have a significant impact on the resin impregnation step as the local permeabilities (in-plane and transverse) of the reinforcement may be affected. In the most severe cases, the ply of fabric can wrinkle or lose contact with the mould, hence severely reducing the quality of the finished product [8]. Consequently the quality of the preform is of vital importance for the final properties of the composite part. During the forming stage, experimental [9] and numerical works [10], conducted on carbon woven fabrics used for aeronautics applications showed that the deformations of the woven textile are complex. Biaxial tensile deformation, in plane shear deformation, transverse compaction and out-of-plane bending deformations can take place during the forming of woven fabrics. All these 
deformations can be significant. However, the shear angle can reach large values (up to $50^{\circ}$ ). The tensile strains remain small (1.5\% for a carbon fabric) [11]. In this paper, an analysis of the reinforcement deformability during the forming process of a woven fabric made from flax fibres is proposed.

\section{EXPERIMENTAL SET UP}

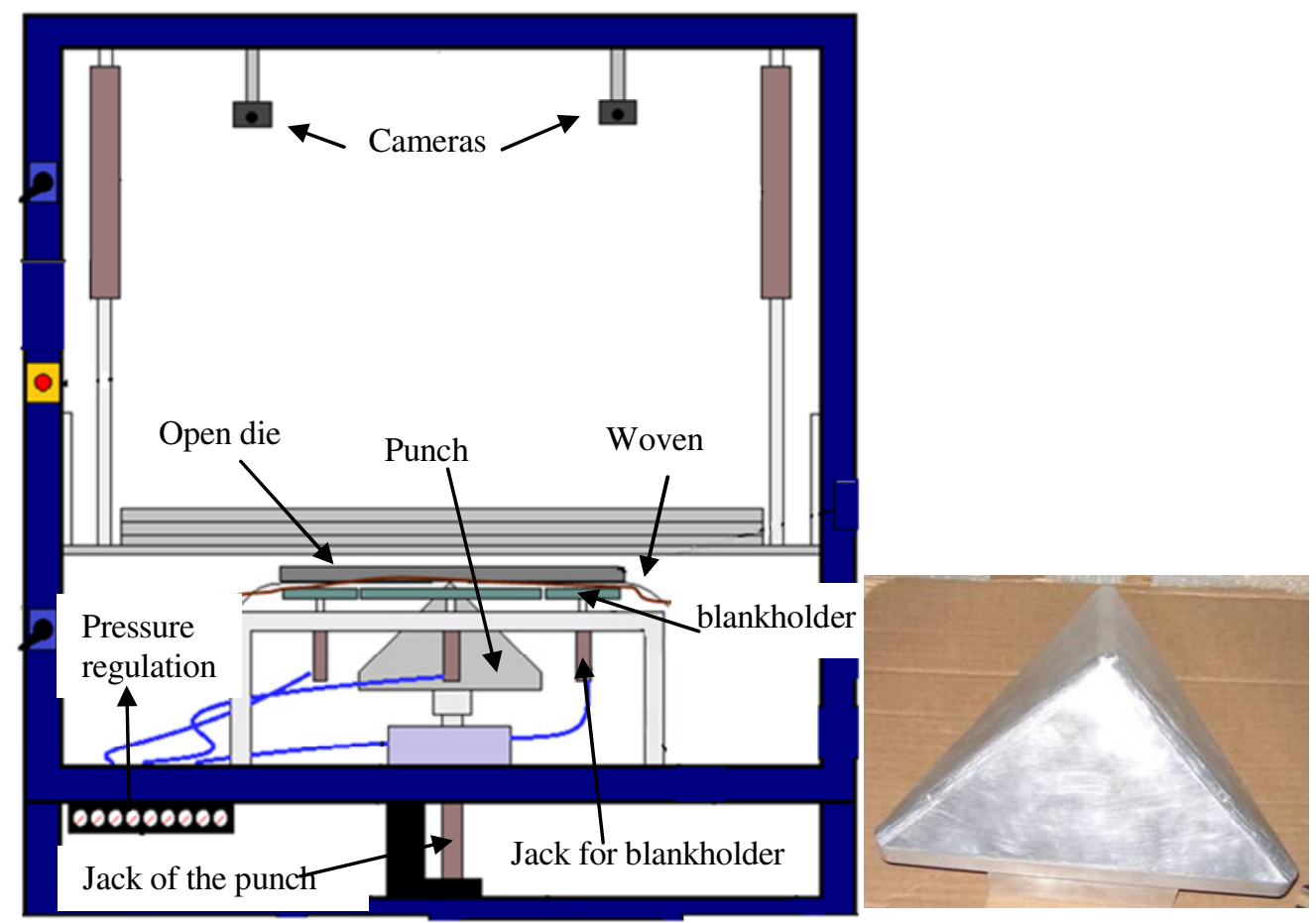

Figure 1. (a) Description of the device. (b) Tetrahedron punch.

A device specifically designed to observe the local strains during the forming of reinforcement fabrics [12] is presented on Figure 1.a. It is constituted of two parts. The mechanical part consists of a punch/open die couple and a classical blank holder system. The die is opened to allow the direct observation of the local strains during the forming process. The motion of the punch is given by a piloted electric jack. Nine independent blank holders associated to pneumatic jacks can be activated under the woven flat fabric. Dimensions, positions, and specifically variable pressure on each of these blank holders can be easily changed to investigate their influence on the quality of the final preform. This device has been developed to preform different shape. Consequently several couple of punch and die can be easily adapted. Severe double curved shapes containing faces, edges and triple points at the intersection of the edge are considered. The goal of the study is to analyze the possibilities of forming severe shapes with new woven fabrics. The tetrahedron punch used in this work is presented on figure 1.b.

The second part of the device is a 3D Digital Image Correlation system. Two numerical cameras are placed at the top of the device. They are located to analyzing specific zones of the fabric. A mark tracking technique [13] is used to compute the displacement field. A speckle pattern needs to be applied on the fabric surface before the test. Generally, dots of paints are applied. The displacement field of these dots marked on fabrics is computed from each digital image of the cameras during the process. From the displacement field, the strain components are deduced in the tangential plane of the fabric. The in plane shear is computed from the modification of the yarn orientation. During the preparation, the marking phase on yarns requires a specific attention. Points must be placed exactly at the top of the yarns. For the flax woven specimen several tests have been conducted to investigate the color that gives a good contrast on camera captions. 


\section{EXPERIMENTAL RESULTS}

\section{Materials Properties and Conditions of the Test}
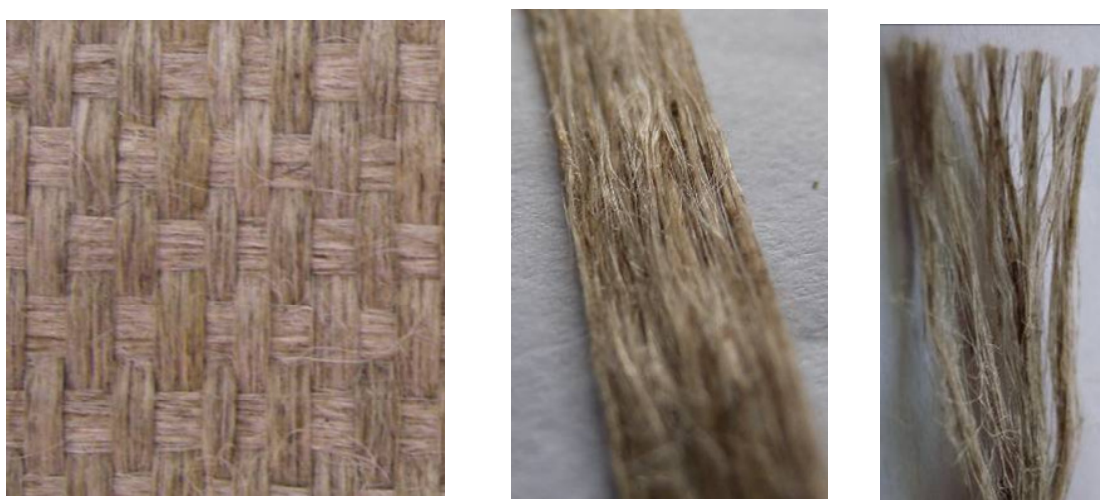

Figure 2. (a) Fabric. (b) Yarn. (c) Constitution of yarns

The flax fabric (figure 2.a) used in this study is a plain weave fabric which areal weight is of about $625 \mathrm{~g} / \mathrm{m}^{2}$. The fabric is not balanced as the yarns in the warp direction are larger (3-4 mm) than those in the weft direction $(2,8$ $\mathrm{mm}$ ). Consequently distance between yarns in the warp distance is more important. This fabric is constituted of yarns (figure 2.b) made of about 1000 fibres each. This constitution aspect is very important for the mechanical behaviour at the scale of the fabric. During the forming process the fabric is submitted to tensile loads in the yarn directions and also to in-plane shear loading. Defects at the scale of the preform such as wrinkles may appear when limit loading is exceeded. Local defects may also appear in specific zones of the form. To characterize the loading limits associated to the appearing of defects at the preform scale, it's necessary to identify the mechanical behaviour of the fabric and of the yarns by using the appropriate tools. . At the scale of the fabric the biaxial tensile behaviour can be identified with a specific device available in our laboratory. The in plane shear behaviour can be identified by a bias-test or by a "picture frame" test. This latest approach has been conducted during previous studies on carbon reinforcements [11] but in this study the bias test approach has been used.

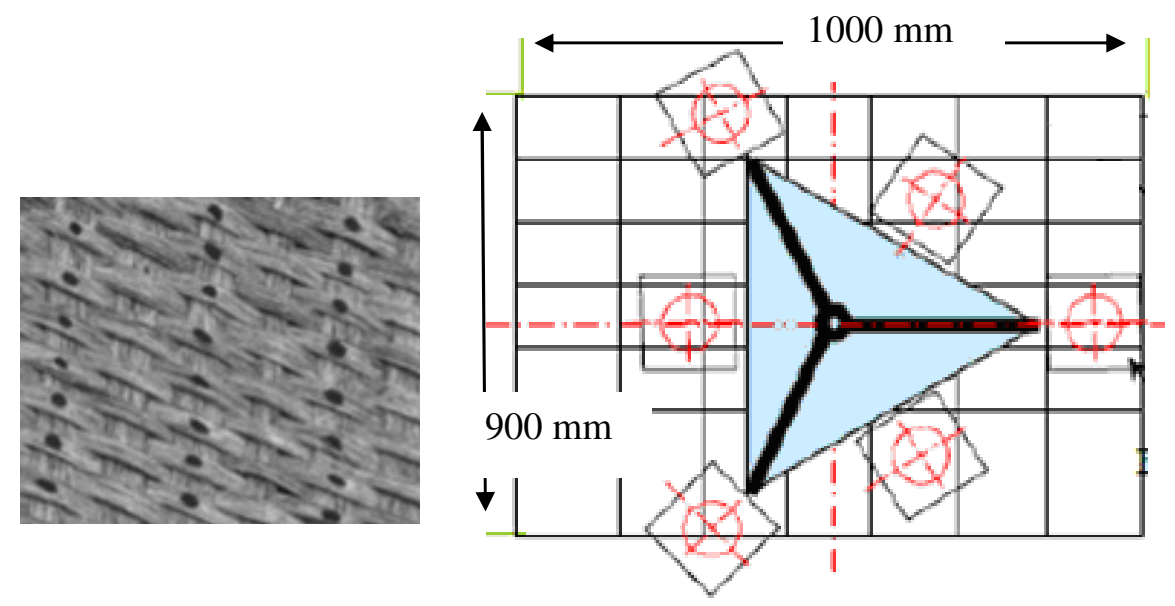

Figure 3. (a) Painted point on fabric. (b) Initial position.

To conduct the preforming tests, an initial rectangular specimen of the flax fabric needs to be prepared. Dots of paint are applied on the surface of the fax fabric (Figure 3.a) before the test. The flat rectangular specimen is placed on the device so that the yarns are parallel to the frame of the open die (Figure 3.b). Six blank holders were used for these tests placed on specific places around the tetrahedron. On each of them a pressure of one bar is applied. The 
maximum depth of the punch is $150 \mathrm{~mm}$. These process parameters (number and position of blank holders, choice of the punch, etc...) and the initial positioning of the fabric have a significant influence on the deformability analysis of the studied woven fabric. These aspects will be studied in future works. For this series of tests, cameras have been headed to look at a specific face of the preform. At the end of the forming process, an epoxy resin spray is applied to the preform so that the shape is fixed in its deformed state.

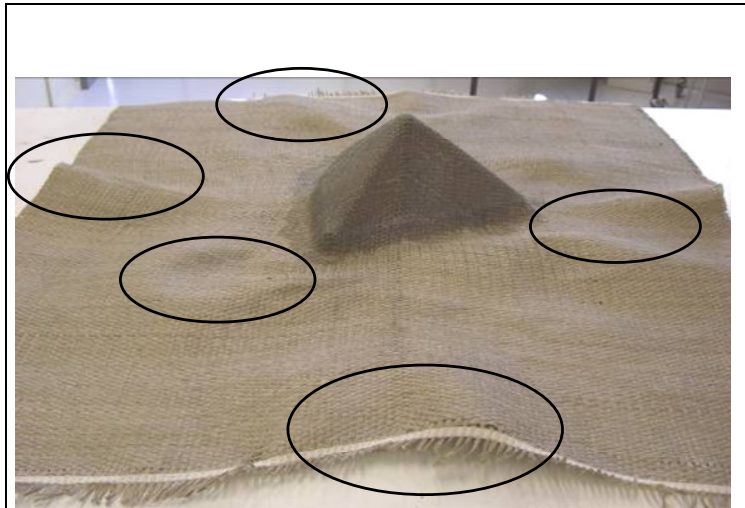

(a)

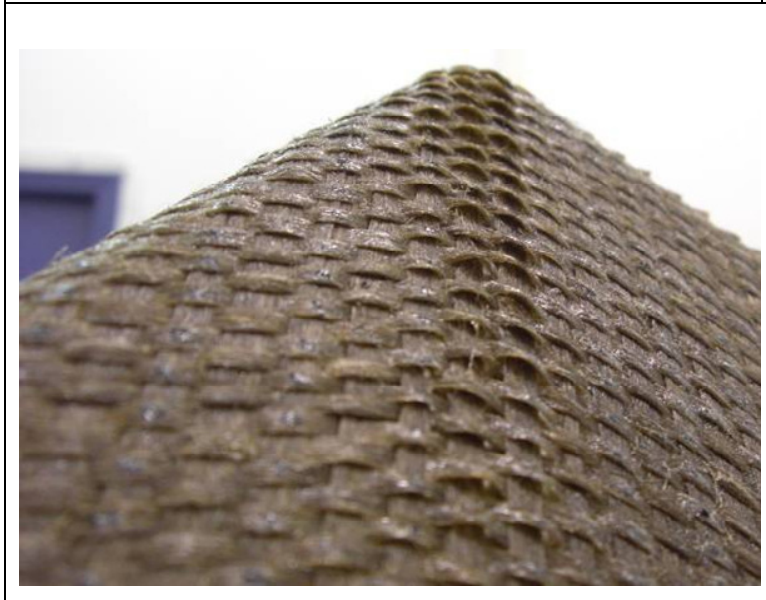

(c)

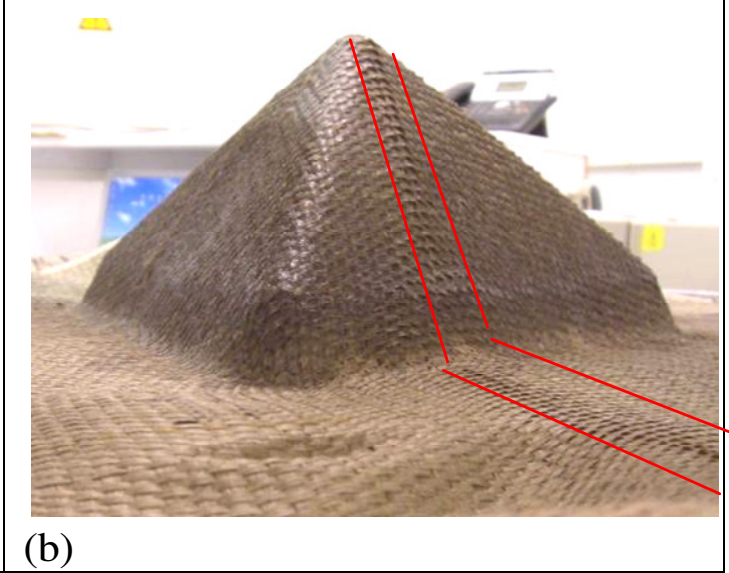

(b)

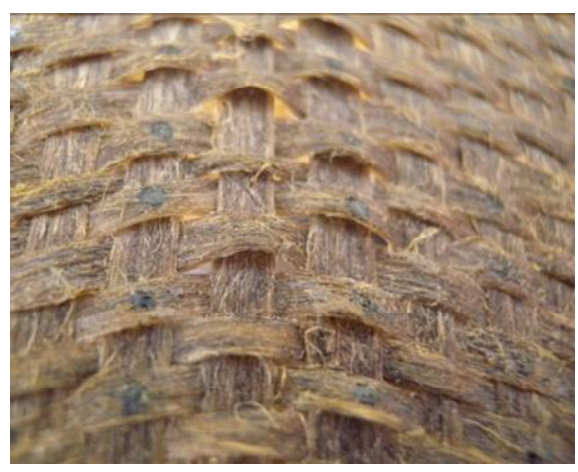

Figure 4. (a) Wrinkles. (b) Position of buckles. (c) Zoom on buckles.

\section{Analysis of the Preform}

Pictures of one of the obtained shapes are presented on figure 4. At the scale of the preform the obtained shape is correct and well shows the expected tetrahedron. The fabric is not un-weaved on faces or edges. Some wrinkles appear (Figure 4.a) around the useful part of the preform. The position and the size of these wrinkles depend on the blank holder position and on the pressure they apply on the fabric. From the triple point (top of the preform), another type of default denoted by buckles appears on two edges and two opposite faces (Figure 4.b). This phenomenon is the consequence of the biaxial tensile behaviour of the woven fabric. Observations made on Figure $4 \mathrm{c}$ showed yarns passing by the triple point are submitted to an important tensile load. Buckles are constituted by the out of plane bending of the yarns (figure 4.d) in the perpendicular direction of the yarns submitted to important loads and is due to the woven nature of the fabric. Due to the thickness in-homogeneity generated by these buckles, this defect cannot be accepted. 


\section{Analysis of in Plane Shear}

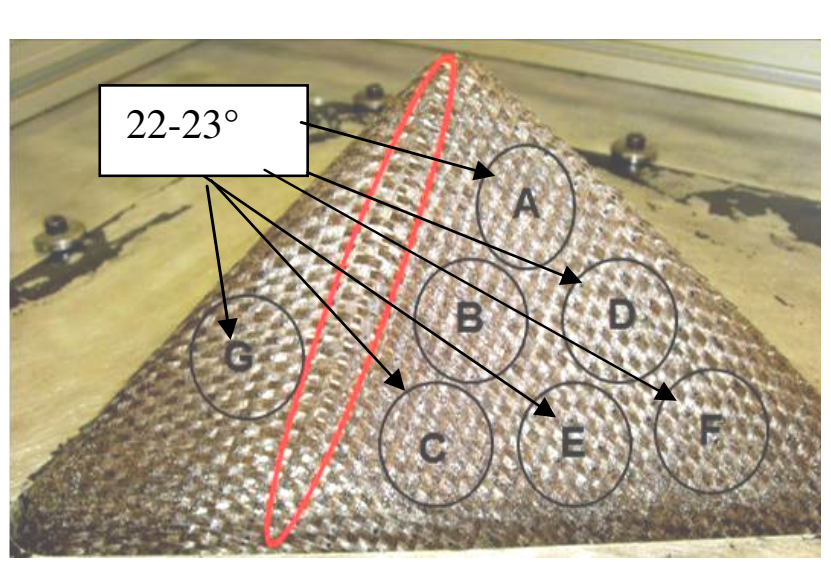

Figure 5. (a) Shear angle on one face of the preform.

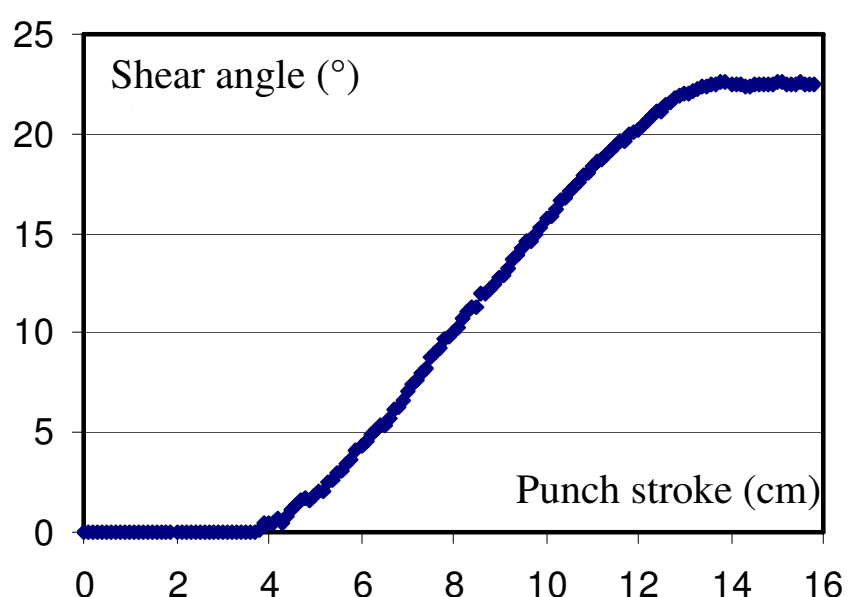

(b) Evolution of shear angle during the process.

By using the mark tracking method, supported by dedicated software, it is possible to study the position of the marks during the whole preforming stage. The strains, in the plane of the fabric, can be deduced. The shear angles between yarns can also be computed. A map of the shear angles of the studied zone can be drawn at each instant of the process to deduce the homogeneity of the shear strain component. Figure 5.a displays the experimental shear angles at the end of the process on one face of the tetrahedron shape. These values were measured on different zones of this face, as mentioned in Figure 5a. A good homogeneity of this strain component has been observed. On this face, yarns in both directions are very tight except in the buckle area. On this buckle zone because some yarns are out of plane it's not possible to evaluate the shear angle with accuracy. One advantage of the device consists in obtaining the evolution of quantities during the process. Figure 5.b, (for the zone A) shows the evolution of the shear angle as a function of the punch displacement. On this curve at low punch displacement, the computed shear angle remains at 0 . This is due to the fact that up to a punch displacement of about $4 \mathrm{~cm}$, the dots of paint of that zone were hidden for the cameras at the beginning of the process. On this face, the presence of wrinkle has not been observed and one can therefore deduce that the locking angle, value of the shear angle from which this type of defects appears [14], is not reached.

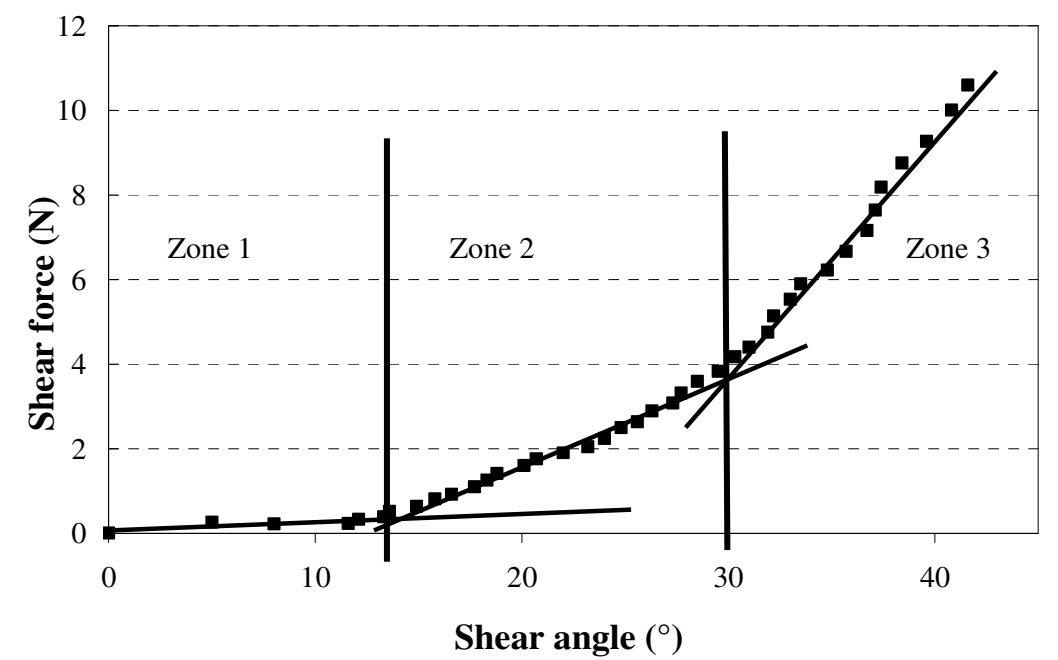

Figure 6: Evolution of the shear force as a function of the shear angle from a BIAS test

This analysis is confirmed by the specific analysis of the in plane shear performed on a Bias extension test [15]. Figure 6 shows the three characteristic zones usually observed during in plane analysis of woven fabrics. In zone 1, 
the stiffness of the fabric is week, and the yarns can easily rotate. The low stiffness is due to yarn-yarn frictions. In zone 2, lateral contact and compression between neighbouring yarns takes place. A stiffness that can be non-linear is observed up to defined angle called the locking angle. From that angle, the stiffness rises again, and out of plane bending of the fabric takes place due to its week bending stiffness. As a consequence, wrinkles may appear in the faces of the fabric. For the flax woven fabric studied in this work, Figure 6 shows that the value of the locking angle can be estimated to be around $30^{\circ}$. This value confirms that the values of shear angle observed on the faces of the tetrahedron are lower than the locking angle. It is therefore normal that no wrinkles due to high shear angles appeared in our preform.

\section{CONCLUSIONS}

In this study a study investigating the possibilities of forming complex shapes from a woven fabric made of flax fibres has been presented. A specific device, developed with EADS-IW for aeronautical applications and used until now to study the deformability of carbon reinforcements, has been used to analyze the link between the preform defects, the yarns orientation and the mechanical behaviour of the fabric. Globally, the complex shape with double curves and a triple point has been obtained. However, buckle defects are observed. In order to get rid of these defects, it may be interesting to investigate the effect of increasing the pressure of specific blank holders. However, increasing the pressure of blank holders may induce high tension loads of the yarns in certain zones, and it therefore becomes necessary to identify the mechanical behaviour of yarns (uni-axial tension) as well as the bi-axial behaviour of the fabric. It is also important to work in collaboration with the textile manufacturer to optimize the constitution and the manufacturing process of the yarns, as well as the architecture of the fabric so that complex shapes may be formed without defects.

\section{REFERENCES}

1. Wambua P., Ivens J., Verpoest. "Natural fibres: can they replace glass in fibre reinforced plastic?" Composite Science and Technology. 63:1259-1264 (2003).

2. Baley C. "Analysis of the flax fibres tensile behaviour and analysis of the tensile increase" Composite Part A. 33:2143-2145 (2002).

3. Bodros E., Baley C. "Study of the tensile properties of stinging nettle fibres" Materials Letters. 62:2143-2145 (2008).

4. Alawar A., Hamed A.M., Al-Kaabi K.. "Characterization of treated data palm tree fiber as composite reinforcement" Compositse Part B. 40:601-606 (2009).

5. Kim J.T., Netravili A.N. "Mercerization of sisal fibers: Effects of tension on mechanical properties of sisal fibers and fiberreinforced composites" Composite Part A. doi:10.106/j.compositea.2010.05.007.

6. Virk A.S., Hall W., Summerscales J. "Failure strain as the key design criterion for fracture of natural fibre composite" Composite Science of Technology. 70:995-999 (2010).

7. Buntain M.J.,Bickerton S. "Modeling forces generated within rigid liquid composite moldings tools. Part A: Experimental study" Composites Part A. 38:1729-1741 (2007).

8. Sharma S.B., Sutcliffe M.P.F., Chang S.H.. "Characterisation of material properties for draping of dry woven composite material" Composites Part A. 34:1167-1175 (2003).

9. Hivet G., Allaoui S., Soulat D., Wendling A., Chatel S. Analysis of woven reinforcement performing using an experimental approach. Proceedings of the 17th International Conference on Composite Materials (ICCM17) 27 Jul 2009 - 31 Jul 2009 , Edinburgh, UK.

10. Boisse P., Hamila N., Helenon F., Hagege, B., Cao J. "Different approaches for woven composite reinforcement forming simulation " International journal of Material Forming. DOI: 10.1007/s12289-008-0002-7.

11. Launay J., Hivet G. Duong A.V., Boisse P. "Experimental analysis of the influence of tensions on in plane shear behaviour of woven composites reinforcements". Composite Science and Technology 68: 506-515 (2008).

12. Soulat D., Allaoui S., Chatel S. "Experimental device for the preforming step of the RTM process". International Journal of Material Forming 2 (1) 181-184 (2009).

13. Launay J., Lahmar F., Boisse P., Vacher P.. "Strain measurement in tests of fibre fabric by image correlation method". Advanced Composite Letters 11, (1), 7-12 (2002).

14. Allaoui S., Hivet G., Wendling A., Soulat D., Chatel S. "Experimental approach for optimizing dry fabric formability" 14th European Conference on composite Materials. 7-10 June 2010, Budapest, Hungary.

15. Cao J. et al. "Characterization of mechanical behavior of woven fabrics: Experimental methods and benchmark results". Composites: Part A; 39: 1037-1053, (2008). 